\title{
Histological and Immunohistochemical Study of Osteocalcin to Evaluate The Effect of Local Application of Symphytum Officinale Oil on Bone Healing on Rat Ansam Mahdi Khalel (BDS) ${ }^{1}$ and Enas Fadhil $(\mathrm{BDS}, \mathrm{MSc}, \mathrm{PhD})^{2}$
}

\begin{abstract} pharmacist and physicians to form the theoretical foundations in Medicine. it was very effectiveness. days after surgery (ten rats for each period). group. a possible clinical management in future.

Keywords: Bone defect, symphytum officinale oil, osteocalcin.

Corresponding Author: arwa11998811@gmail.com

Received: $2^{\text {nd }}$ October 2019

Accepted: $29^{\text {th }}$ October 2019

DOI:https://doi.org/10.26505/DJM.18024981002
\end{abstract}

Background: The repair of bone defects remains a major clinical challenge in dentistry. Bone is a highly vascularized tissue reliant on the close spatial and temporal connection between blood vessels and bone cells to maintain skeletal integrity. The health promotive , preventive, and curative properties of herbs were recognized by the ancient and the present

Objective: Immunohistochemistry of osteocalcin and histological study to prove that symphytum officinale oil when applied locally on generated bone defect healing in rat tibia,

Patients and Methods: Our study fourty male rats, weighting (250-350) grams ,aged (57)months, was performed under same food and drinking utilization with same temperature conditions. The surgical operation of tibiae bone to medial side of rat were subjected, the bone defect were left to cure normally in control group, whilst experimental group was applied $1 \mu \mathrm{m}$ symphytum officimale oil locally as a treatment. Every rat was killed at 7 or 14

Results: When we applied the symphytum officinale oil locally on bone defect increased cell count in each of osteocyte ,osteoclast and osteoblast and deposed of early osteoid tissue . stromal cells evaluated by Immunohistochemical study of osteocalcin which reported to increase in significant difference in symphytum officinale group when compared to control

Conclusion: Low application of symphytum officinale oil in our study expressed to be a good and effective treatment in injuries of bone; these evidence in our data are pledging for

${ }^{1,2}$ Collage of Dentistry - University of Baghdad- Baghdad -Iraq. 


\section{Introduction}

Bone is a specialized and mineralized connective tissue which involves constant cycles of bone formation combined with bone resorption that called remodeling. The cooperative roles of bone formation and resorptive cells to repair the structure and function of defect bone tissue that means healing of bone tissue has considerable potential [1]. A complex interaction between various anatomical, biochemical and biomechanical processes are involved in bone healing . Skeletal repair, different from a lot of other tissues, can restore of the biochemical and biomechanical properties of the defected bone tissue completely. Bone is unique that regenerated without a fibrous scar. Although skeletal tissue has a powerful restorative capacity [2].

The information of the medicinal amount and uses of plants and herbals are went back to the ancient colonists. Folk medicine practice is again coming in a new form for the well-being of the patients. The key standard in the treatment of fracture is antiinflammation action which is the principle of traditional bone setters' past time [3].

Symphytum officinale is used in plant medicine that also called as knitbone and bone-set, these names precisely illuminate the field of treatment genius, the repairing of broken bones, and the mending of bone diseases which include osteitis (inflammation of the bones) and also help in cancers of the bones or sarcomas. Symphytum officinale is widely treated periosteum ,cartilage and tendons [4]. Symphytum officinale has pharmacological materials which mainly comprise of rosmarinic acid and tannin. Other constituents of symphytum root include chlorogenic acid, caffeic acid and ahydroxy caffeic acid . The efficacy of synphytum is primarily suggested to its analgesic, anti-inflammatory, antiexudative properties and granulation promoting [5]. Osteocalcin is a one of non-collagenous organic material and a $\mathrm{Ca} 2+$ binding protein that comprised about $10-20 \%$ in extracellular bone matrix, where it is mainly synthesized in osteoblasts. A specific marker of the mature osteoblast phenotype is the Osteocalcin [6] . Osteocalcin can detect ahead the bone matrix of lamellae of delicate granular precipitation and mainly detect in osteoblast and osteocytes. Intense immunochemical reaction of osteocalcin can show in the osteoclasts cell margins and the Howship lacunae bone borders [7]. osteocalcin is detected in older flat osteoblasts higher than in cuboidal active osteoblasts. Osteocalcin is undetected in the conditioned bone tissue before day 7 and reached higher approximately day 14 in bone cells [8]. In consequence the our study which was planned to evaluate bone healing when was applicated symphytum officinale oil locally and immunohistochemical expression of osteocalcin on bone marrow stromal cells.

\section{Patients and Methods}

In agreement with the animal experimentation of ethical principles which carried out all experimental procedures . The animal department of veterinary medicine collage in kufa university /Najaf - IRAQ in separate cages in a12:12 hour light/dark 
Histological and Immunohistochemical Study of Osteocalcin to Evaluate The Effect of Local Application

of Symphytum Officinale Oil on Bone Healing on Rat

environment at a constant humidity and temperature of $\left(23^{\circ} \mathrm{C}\right)$ according to the National Research Council's guide for the care and use of laboratory animals. In our study, fourty male rats that was white Albino, aged (5-7) months, weighting (250-350) gram were utilized and hold in regulation in requirement of same temperature, food consumption and drinking. The animals were subdivided into two groups each individual group consists of 20 rats. The rats were killed at 7,14 days after surgical operation (10 rats for each period).

In the research, the materials applied were:

1-Symphytum officinale oil from avena company (UK).

2-Anti-Osteocalcin antibody [OCG3] ab13420 abcam company.

\section{Surgical procedure}

The rats were administrated for a surgery. The operation was performed in gentle soft procedure and under a sterile operating room. The dose of general anesthesia is calculated by weighting the rat which was supplied to it. The Intra muscular injection of general anesthesia was induced by ketamine Hydrochloride 50mg (40 mg/kilogram- Body Weight.) and xylazine 2\% (0.4 mg/kilogram Body Weight.) was also given an tetracycline $20 \%(0.7 \mathrm{ml} /$ kilogram $)$ as an antibiotic cover intramuscular injection.

Right tibia was shaving and the skin was cleaning with a combination of iodine and alcohol. Incision was made and the flap of skin and muscle was reflecting. A $1.88 \mathrm{~mm}$ bone defect was madding By using instrument drilling and small-sized round bur at a $1500 \mathrm{rpm}$ rotary speed with continuous cooling with irrigated normal saline.

The hole operating defect was washing to clean the operating site with normal saline then drying the hole area by sterile guaze and applied $1 \mu \mathrm{m}$ (by micropipette) symphytum officinale oil in experimental group, while the bone in control group was leaving to heal normally. Suturing was done in two step which include suturing the muscle by catgut which is absorbable, then skin was suturing by silk. The surgery hole was applied tetracycline spray as antibiotic locally.

\section{Histological Specimen preparation}

The specimens were fixed about 24 hours in $10 \%$ formalin then put in solution of formic acid to decalcify the specimens, and was been dehydrating by alcohol and implanted in wax (paraffin). Section of 4$5 \mu \mathrm{m}$ was processed in the common architecture, with hematoxylin and Eosin was stained. Light microscope was using to evaluate histological research.

\section{Immunohistochemistry results Assessment}

When the brown cytoplasmic stain expressed in cells that mean positive reading was indicated, while lack of immunoreactions that mean negative reading rely upon on negative and positive control.

\section{Statistical analysis}

For bone cells count in histological research calculate by Min., Mean, Max., F-test, S.D, $\mathrm{P}$-value. For bone stromal cells count which diplayed by osteocalcin was calculated by Min., Mean, Max., F-test, S.D, P-value Tables(1) and (2). 


\section{Results}

A-Histological findings

1-For control group

At 7 day interval, Bone healing site demonstrates articulation tissue, with reticular cells and progenitor cells and the new matrix bone entrapped osteocyte cells in it with active osteoblasts are rimming it Figure(1). At 14 days duration, new bone trabeculae was building and fused with basal bone with osteoblast at periphery and

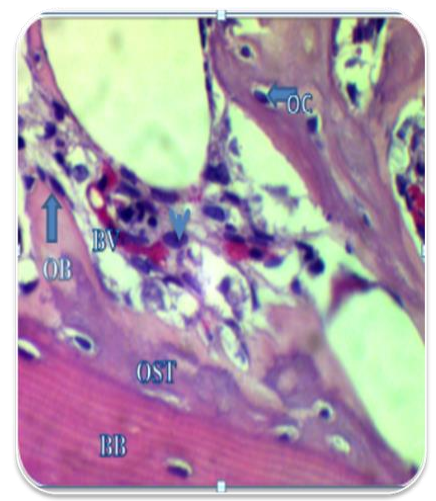

Figure (1): View of control group after7 days, demonstrates basal bone (BB) with osteoid tissue (OST), osteoblasts (OB), and progenitor cells (arrow head) near blood vessel . H\&E $\mathrm{X} 40$.

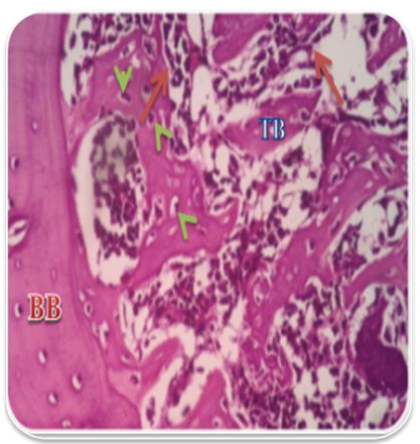

Figure (3): Photograph of 7 days of symphytum group shows basal bone (BB) and bone trabeculae (TB) with numerous osteocyts (arrow heads), osteoblast (arrows). H\&E 40X . osteocyte inside it and reticular cells were also demonstrated Figure(2).

2-Symphytum oil group showed cutting bone coalesce with new bone trabeculae with osteoblast and osteocyte cells which were showed in symphytum officinale oil group 7 days with osteoid tissue that is highly vascular Figure(3).

In 14 days basal bone fuse with new trabecular bone with multiple haversian system in symphytum oil group Figure(4).

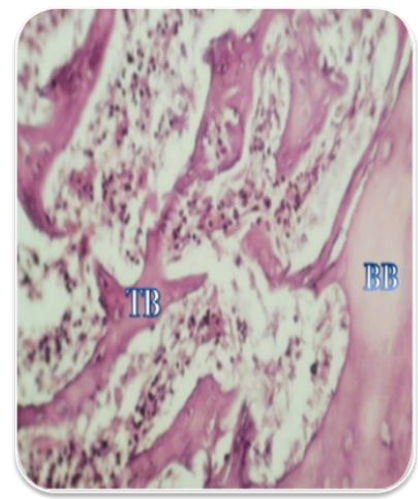

Figure (2): Photograph of 14 days in control group for osteocyte cells entraped in new trabeculated bone (TB) and basal bone (BB). H\&EX20.

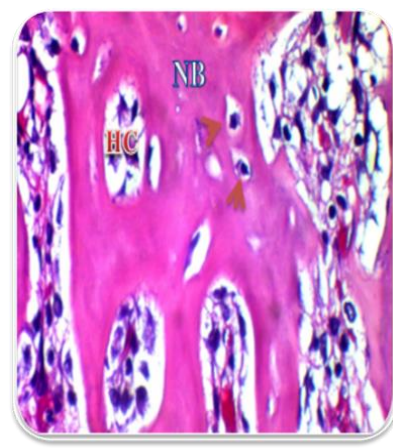

Figure (4): View of 14 days symphytum group shows new bone (NB) with haversian canal (HC) and osteocyte (arrow heads). H\&EX40 


\section{B-Immunohistochemical findings}

1- Osteocalcin expressed in control group Immunohistochemistry expression at 7 days interval for control group, a positive expression of osteocalcin by osteoblast ,osteocyte and progenitor cells Figure (5). At 14 days interval, osteoblast, fibroblast cell and active osteocyte cell positive osteocalcin expression demonstrate in osteoblast, and

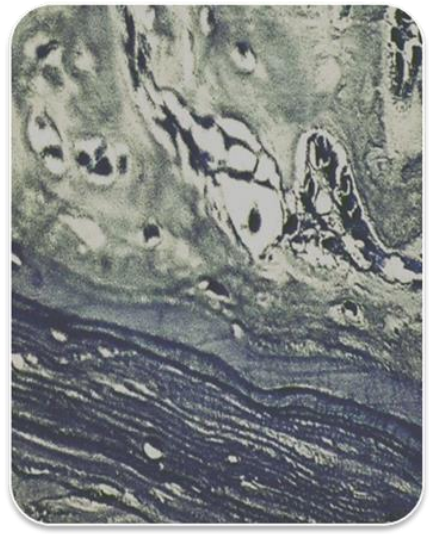

Figure (5): Positive OC expression show osteoid, osteocyte (arrow heads ) and osteoblast (arrow) show in control group 7 days. DAB stainX40

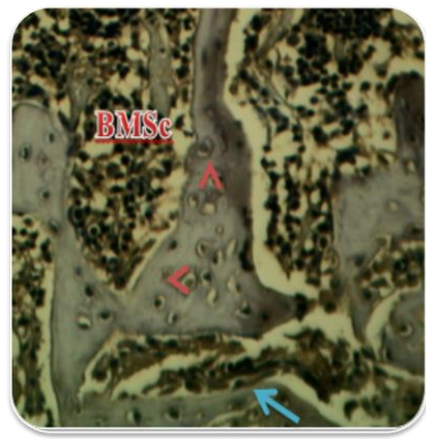

Figure (7): Immunohistochemical view for positive OC expression in symphytum group 7days show osteocyte cells (arrow heads), osteoblast cells (arrows) and bone marrow stromal cells (BMSc). DAB stainX20 active osteocyte cell and in stromal cells , Figure (6).

2- Osteocalcin is expressed in symphytum officinale groups slides at 7 and 14 day periods show osteoblast, active osteocyte and osteoclast with bone marrow stromal cells show positive osteocalcin expression Figure $(7,8)$.

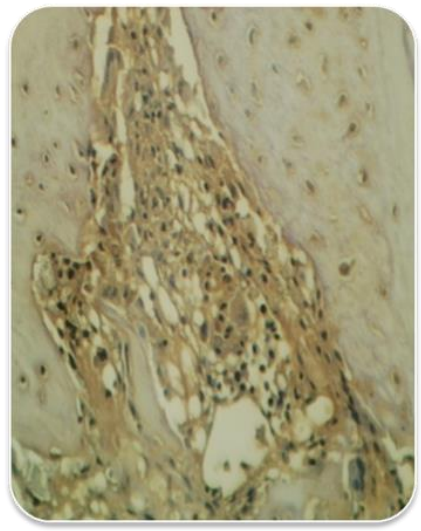

Figure (6): Positive OC expression at 14 days in control group demonstrate osteocyte(arrow heads), with osteoblast (arrows). DAB stainX20

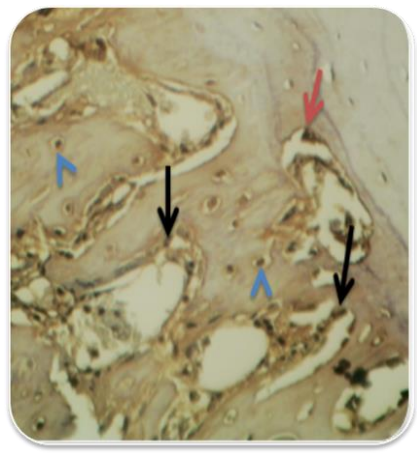

Figure (8): Positive OC expression in symphytum group 14 days demonstrate osteoblast cells (arrow), osteocyte cells (arrow heads), osteoclast (red arrow). DAB stainX20 
Histological and Immunohistochemical Study of Osteocalcin to Evaluate The Effect of Local Application of Symphytum Officinale Oil on Bone Healing on Rat

C. Analysis of Statistical data

Histological analysis

Statistical analysis for bone cells mean count comprise of osteoclast osteoblast, osteocyte in two 7 and 14 days interval, demonstrates the symphytum officinale oil groups show an increasing mean value with highly significant differences when compared with control groups, Table (1).

Table (1): Descriptive statistics of the bone cells count (H\&E) and groups' difference in each duration

\begin{tabular}{|c|c|c|c|c|c|c|c|c|}
\hline \multirow[b]{2}{*}{ Bone cells } & \multirow[b]{2}{*}{ Duration } & \multirow[b]{2}{*}{ Groups } & \multicolumn{4}{|c|}{ Descriptive statistics } & \multicolumn{2}{|c|}{ Group Difference } \\
\hline & & & Mean & S.D & Min. & Max. & F-test & $\begin{array}{c}\mathrm{P} \\
\text { value }\end{array}$ \\
\hline \multirow[t]{2}{*}{ Osteoblast } & \multirow[t]{2}{*}{7 days } & Control & 9.15 & 1.557 & 6.00 & 9.50 & \multirow[t]{2}{*}{72.00} & \multirow{2}{*}{$\begin{array}{r}0.000 \\
(\mathrm{HS})\end{array}$} \\
\hline & & SO & 15.75 & 1.242 & 6.00 & 8.75 & & \\
\hline \multirow{2}{*}{ Osteoblast } & \multirow{2}{*}{14 days } & Control & 8.50 & 0.802 & 8.25 & 10.25 & \multirow{2}{*}{3.246} & \multirow{2}{*}{$\begin{array}{c}0.009 \\
\text { (HS) }\end{array}$} \\
\hline & & $\mathrm{SO}$ & 7.00 & .612 & 15.00 & 16.50 & & \\
\hline \multirow[t]{2}{*}{ Osteocyte } & \multirow[t]{2}{*}{7 days } & Control & 9.95 & 0.918 & 6.25 & 8.50 & \multirow[t]{2}{*}{25.18} & \multirow{2}{*}{$\begin{array}{r}0.000 \\
(\mathrm{HS})\end{array}$} \\
\hline & & SO & 13.15 & 2.081 & 7.75 & 13.25 & & \\
\hline \multirow{2}{*}{ Osteocyte } & \multirow{2}{*}{14 days } & Control & 7.50 & 1.4186 & 8.50 & 12.00 & \multirow{2}{*}{12.61} & \multirow{2}{*}{$\begin{array}{c}0.000 \\
\text { (HS) }\end{array}$} \\
\hline & & SO & 11.60 & 0.353 & 13.75 & 14.50 & & \\
\hline \multirow[t]{2}{*}{ Osteoclast } & \multirow[t]{2}{*}{7 days } & Control & 0.25 & 0.325 & 0.25 & 1.00 & \multirow[b]{2}{*}{2.51} & \multirow{2}{*}{$\begin{array}{r}0.009 \\
\text { (HS) }\end{array}$} \\
\hline & & SO & 0.40 & 0.418 & 0.00 & 2.00 & & \\
\hline \multirow{2}{*}{ Osteoclast } & \multirow{2}{*}{14 days } & Control & 0.55 & 0.547 & .75 & 2.00 & \multirow{2}{*}{15.84} & \multirow{2}{*}{$\begin{array}{c}0.000 \\
\text { (HS) }\end{array}$} \\
\hline & & SO & 1.60 & 0.379 & 1.00 & 1.00 & & \\
\hline
\end{tabular}

* HS: Highly Sig. at P<0.01; S: Sig. at $\mathrm{P}<0.05$; NS: Non Sig. at P>0.05

\section{Immunohistochemical analysis}

The osteocalcin expressed in positive for lepidium sativum group when compared stromal cells in two studied groups, statistical with control group that shows in (7 and 14 analysis illustrated a high significant value days) intervals as shown in Table (2).

Table (2): Descriptive statistics of the positive stromal cells expressed by osteocalcin and groups' difference in each duration

\begin{tabular}{|c|c|c|c|c|c|c|c|c|}
\hline & \multirow{2}{*}{ Duration } & \multirow{2}{*}{ Groups } & \multicolumn{4}{|c|}{ Descriptive statistics } & \multicolumn{2}{|c|}{ Group difference } \\
\hline & & & Mean & S.D & Min. & Max. & F-test & $P$ value \\
\hline \multirow{4}{*}{ BMSC } & \multirow{2}{*}{7 days } & Control & 20.80 & 3.89 & 16.00 & 26.00 & \multirow{2}{*}{4.768} & \multirow{2}{*}{$\begin{array}{c}0.005 \\
\text { (HS) }\end{array}$} \\
\hline & & $\mathrm{SO}$ & 28.60 & 2.73 & 25.75 & 33.00 & & \\
\hline & \multirow{2}{*}{14 days } & Control & 11.50 & 3.57 & 8.00 & 17.00 & \multirow{2}{*}{11.07} & \multirow{2}{*}{$\begin{array}{c}0.000 \\
\text { (HS) }\end{array}$} \\
\hline & & $\mathrm{SO}$ & 20.80 & 3.05 & 16.75 & 24.50 & & \\
\hline
\end{tabular}

*F HS: Highly Sig. at P<0.01; S: Sig. at P<0.05; NS: Non Sig. at P $>0.05$ 
Histological and Immunohistochemical Study of Osteocalcin to Evaluate The Effect of Local Application

\section{Discussion}

In present study was evaluated the effective of lepidium sativum oil applicated locally which is elicited on experimentally bone tibial injury in rats. The rat was used in a significant proportion $38 \%$ t0 $40 \%$ of animal fracture studies in prominent orthopaedic researches over the last decade [9]. This study demonstrates a bone matrix early deposition and results obtained in this study showed increase in mean count difference of cell numbers in between control and symphytum officinale groups at 7 and 14 days of bone treatment. This agreement with Spin-Neto et al. [10] who reported stimulate bone repair at 14 days when treated with symphytm officinale. This was reflected in the acceleration of the regeneration and maturation in peri-implant bone tissue in rat tibia by radiographic image.

Chandel [11] stated that the enhancement of fracture healing and calcification process in dogs demonstrated by radiographic image is attributed to the therapeutic efficacy of Symphytum officinale homoeopathy drug which it acted as an anti-inflammatory, analgesic drug with specific osteoinductive properties along with the proper fracture fixation technique.

The progression of bone healing was progressed as indicated by osteoid deposition and osteoblasts differentiated through the 7 days with within newly formed bone by trabecular bone formative which is shown by histological slides which leads to increase in width and number of trabeculae through the 14 days periods. Remodeling process is important by The existence of osteoclasts residing Howship lacunae.

Immunoreactivety shows OC does not completely overlap with the nuclei and is secreting osteoid beyond the boundaries of the osteoblast cell in forming bone [12]. Osteocalcin was expressed and localized in the two groups demonstrated brownish color that is meaning ,there was osteocalcin expression, the positive cells were detected at osteocyte, osteoblast, osteoclast in the two groups. As well as the peripheries of the resorptive lacunae and the new bone matrix was also shown a positive osteocalcin expression. This coincided with Alpan et.al., [13] who demonstrated that osteocyte, osteoblast, the peripheries of the resorptive lacunae and osteoid was shown strong positive osteocalcin expression that was suggested active new matrix formation.

\section{Conclusions}

The present study was demonstrated by obtained results that a highly potential activity of symphytum officinale oil as osteoconductive precipitated in promoting bone injuries healing procedure.

\section{References}

[1]Vieira, A. E., Repeke, C. E., Junior, S. D. B. F., Colavite, P. M., Biguetti, C. C., Oliveira, R. C., ... \& Garlet, G. P. (2015). Intramembranous bone healing process subsequent to tooth extraction in mice: micro-computed tomography, histomorphometric and molecular characterization. PloS one, 10(5), e0128021. [2]Buza III, J. A., \& Einhorn, T. (2016). Bone healing in 2016. Clinical Cases in 
Histological and Immunohistochemical Study of Osteocalcin to Evaluate The Effect of Local Application

of Symphytum Officinale Oil on Bone Healing on Rat

Mineral and Bone Metabolism, 13(2), 101. [3]Singh, V. (2017). Medicinal plants and bone healing. National journal of maxillofacial surgery, 8(1), 4 .

[4]Alkan, F. U., Anlas, C., Ustuner, O., Bakırel, T., \& Sari, A. B. (2014). Antioxidant and proliferative effects of aqueous and ethanolic extracts of Symphytum officinale on 3T3 Swiss albino mouse fibroblast cell line. Asian J Plant Sci Res, 4(4), 62-8.

[5]Sowa, I., Paduch, R., Strzemski, M., Zielińska, S., Rydzik-Strzemska, E., Sawicki, J., ... \& Wójciak-Kosior, M. (2018). Proliferative and antioxidant activity of Symphytum officinale root extract. Natural product research, 32(5), 605-609.

[6]Vermeulen, A. H., Vermeer, C., \& Bosman, F. T. (1989). Histochemical detection of osteocalcin in normal and pathological human bone. Journal of Histochemistry \& Cytochemistry, 37(10), 1503-1508.

[7]Johari, B., Ahmadzadehzarajabad, M., Azami, M., Kazemi, M., Soleimani, M., Kargozar, S., ... \& Samadikuchaksaraei, A. (2016). Repair of rat critical size calvarial defect using osteoblast-like and umbilical vein endothelial cells seeded in gelatin/hydroxyapatite scaffolds. Journal of Biomedical Materials Research Part A, 104(7), 1770-1778.

[8]Malaval, L., Modrowski, D., Gupta, A. K., \& Aubin, J. E. (1994). Cellular expression of bone-related proteins during in vitro osteogenesis in rat bone marrow stromal cell cultures. Journal of cellular physiology, 158(3), 555-572.
[9]O'LOUGHLIN, P. F., MORR, S., BOGUNOVIC, L., KIM, A. D., PARK, B., \& LANE, J. M. (2008). Selection and development of preclinical models in fracture-healing research. JBJS, 90(Supplement_1), 79-84.

[10]Spin-Neto, R., Belluci, M. M., Sakakura, C. E., Scaf, G., Pepato, M. T., \& Marcantonio Jr, E. (2010). Homeopathic Symphytum officinale increases removal torque and radiographic bone density around titanium implants in rats. Homeopathy, 99(04), 249-254.

[11]Chandel, S. (2014). Role of Symphytum Officinale As An Osteoinducer In Long Bone Fracture Repair In Canine (Doctoral dissertation, MAFSU).

[12]Brownridge III, G. W., Islas, S., Miller, A., \& Hoeffler, W. (2017). Stem Cell Derived Osteoprogenitors and Their Role in Bone Repair Using Morphogenic Activators. [13]Alpan, A. L., Toker, H., \& Ozer, H. (2016). Ozone therapy enhances osseous healing in rats with diabetes with calvarial defects: a morphometric and immunohistochemical study. Journal of periodontology, 87(8), 982-989. 